\title{
Occupational and regional associations of death, disablement, and sickness absence among Post Office staff 1972-75
}

\author{
PETER J. TAYLOR \\ Post Office Central Headquarters, 23 Howland Street, London WIP $6 \mathrm{HO}$
}

\begin{abstract}
Taylor, P. J. (1976). British Journal of Industrial Medicine, 33, 230-235. Occupational and regional associations of death, disablement, and sickness absence among Post Office staff 197275. Rates of death in service and rates of premature retirement due to disability in an employed population of more than 400000 people under the age of 60 years have been compared with duration rates of certified sickness absence for three years from April 1972. Standardized for age, rates of sickness absence and of death, combined with retirement (medical wastage) for men and women differed between 11 occupational groups by a factor of three. Significant rank correlations were observed between these two measures of ill health, $r_{s}=0.827$ for men, $r_{s}=0.857$ for women. Similar comparisons for $1974 / 75$ of rates for staff employed in 10 geographical regions of the United Kingdom standardized for age and occupation, revealed twofold differences of rate, and rank correlation coefficients of +0.794 for men and +0.649 for women. These observations show that the duration of certified sickness absence is higher in groups of people showing other objective evidence of ill health and who are most in need of preventive health care. The need is discussed for a balanced view of the complex aetiology of sickness absence.
\end{abstract}

It is generally accepted that absence from work attributed to incapacity is not a reliable indicator of true morbidity. Ill health is but one among a wide range of factors known to influence both the frequency and the duration of spells of sickness absence (Taylor and Pocock, 1973). This situation is recognized in the problems of medical certification, since it is more often the patient than the doctor who decides when a certificate should be signed (Committee on Abuse of Social Security Benefits, 1973; Coe, 1975). Studies in the Post Office (Bashford, 1944), and more recently a number of authors including Hinkle and Wolff (1957), Taylor (1968), and Jones (1971), have emphasized the importance of individual motivation. Economic, cultural, and occupational attitudes including job satisfaction are now recognized to be of importance, and the last of these is included in one of the main tables concerning sickness absence produced by The
General Household Survey (Office of Population Censuses and Surveys, 1975). There may now be a tendency for some to consider that these psychosocial factors are of overriding importance in the genesis of sickness absence.

While annual analyses of sickness absence are undertaken in many organizations, few are large enough to justify similar studies of death or disablement. The Post Office, one of the largest employers in the United Kingdom, has provided such annual statistics for over 50 years (Long, 1968). This organization is responsible not only for postal services, but also for telecommunications, a national data processing service, and the national giro. With an employee population of some 430000 , about 1500 die in service each year. A similar number of staff are prematurely retired because of long-term disabilities which prevent them from doing their usual work if no other suitable job can be found. 
While preparing recent annual reports on sickness absence, medical retirements, and deaths among Post Office staff positive relationships were noted between absence levels in various occupations and the rates of retirement and death combined. Similar associations were found for staff employed in different geographical regions. This paper describes these observations, which have not previously been reported since they suggest that a more balanced view should be taken of the complex aetiology of sickness absence. This may also have some value as an indicator where needs exist for preventive health action among working populations.

\section{Methods}

The information used in this paper is derived from the records of staff under the age of 60 years for the three years beginning in April 1972.

\section{Occupational groups}

The staff statistics system distinguishes 11 main job or grade groups. Since in four of these only a few women are included, results are described for 11 male and seven female grade groups. Male grades include: senior staff (senior and middle management throughout the Post Office), postal executives, postal clerical and counter staff, postmen higher grade, postmen, other postal staff (which includes catering, cleaning, typing, storemen, and doorkeepers), senior telecommunications engineers, telecommunications technicians, telecommunications office staff, telephonists, and other telecommunications staff(as for 'other postal' but also including factory workers). The numbers employed in each grade group range from almost 4000 senior staff to more than 106000 technicians. Female grades include: postal executives, postal clerical and counter staff, postwomen and other postal staff, telecommunications office staff, telephonists, and other telecommunications staff. Their numbers range from just under 1000 postal executives to more than 32000 telephonists.

\section{Post Office regions}

The geographical boundaries of the organization within the United Kingdom, apart from Scotland and Northern Ireland, are similar to but not quite the same as the standard regions used by government departments and the Office of Population Censuses and Surveys. There is only one Midlands region in the Post Office and 'Wales and the Marches' includes Hereford, Shropshire, and the western half of Cheshire. The Post Office's North East region includes the standard Yorkshire and Humber region and also the eastern half of the standard Northern region, the western half being in the Post Office's North West region. The 10 geographical regions include both postal and telecommunications staff: the numbers employed range from more than 100000 men and 28000 women in London to more than 6000 men and nearly 1500 women in Northern Ireland.

\section{Sickness absence records}

Cards are maintained for every employee on which are recorded full details of every absence attributed to in- capacity, whether medically certified or not, and duration is measured in calendar days. Uncertified absence is permitted for up to 10 working days in one year, provided that any one uncertified spell does not exceed five working days. Sick pay, as full normal wage, is provided from the first day of absence for up to six months and Post Office employees do not claim social security benefit during this time. Statistics of sickness absence are prepared each year from the records of a random sample of staff. These were previously set at $5 \%$, but since 1972 variable fractions of 4,5 , and $10 \%$ have been used according to numbers at risk in various sex, age, and occupational groups. The annual statistics are thus based upon a sample of about 25000 and the information is analysed by a computer of the Post Office's data processing service.

\section{Deaths in service}

These are based upon complete returns and copies of death certificates are obtained in every case since these are required for pension fund purposes. Details of all deaths are analysed by computer for sex, age group, main job grade, and region.

\section{Medical retirements}

Since the normal retirement age for pension purposes is 60 years, this is fully recorded only for staff under this age. Medical retirement is necessary only if the employee has a condition which disables him or her from undertaking the normal duties of the grade and if no suitable alternative job is available. A medical retirement certificate, signed by a full-time doctor of the occupational health service, is required for each case. Analysis is done in the same way as for deaths in service.

\section{Medical wastage}

This is the term used to describe the sum of deaths in service under the age of 60 and of medical retirements. These two outcomes are to a certain extent interchangeable since in the case of a fatal disease there may be some degree of choice whether the patient can continue work or not. Furthermore the process of retirement takes some weeks and death may intervene. Deaths in service do not therefore provide a reliable measure of occupational mortality. Many medical retirements however are caused by non-fatal conditions (psychiatric, musculo-skeletal, etc.) and thus it seemed appropriate to combine rates of death and retirement into an overall rate called 'medical wastage'.

\section{Results}

For the three years 1972-75 the average annual duration of sickness absence per person employed was 14.0 calendar days, of which 1.7 days were due to uncertified absence. This overall figure conceals wide differences between rates for men and those for women in various grades and of different ages. Similarly, the mean rates of death in service at $\mathbf{2 . 8}$ per 1000 and of medical retirement at 4.0 , which together amount to a wastage rate of 6.8 persons per 1000 employed under the age of 60 years, are 
made up from very contrasting rates within subgroups. Not surprisingly, there was a marked age effect for both deaths and retirements which rose very steeply after the age of 50 years for both sexes. The age effect of sickness absence days however was less marked among men (Fig. 1), and almost nonexistent among women. Frequency of sickness absence however followed the well-recognized pattern of decreasing as age increased. These differences in age effect, together with the different age structures of staff in various occupational grades, make age standardization necessary before absence and wastage rates can be compared.

\section{Wastage and absence in occupational grades}

Even after age standardization by the direct method, threefold differences still remained between grade groups within the same sex. Grades with high wastage such as telephonists, postmen, and the other grades in both the postal and telecommunications businesses were found to have the higher rates of absence. These relationships were first assessed by applying Spearman's rank correlation test for wastage against different measures of absence on a man year basis for the year 1973-74. Total days of absence $\left(r_{s} 0.867\right.$ $P<0.01)$ and days of certified absence $\left(r_{s} 0.903\right.$, $P<0.001)$ showed ranking orders for the 11 male grades that were closely similar to wastage. Other

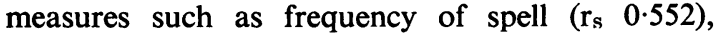

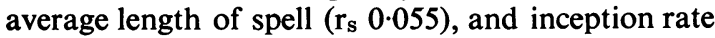
persons $\left(r_{s} 0.491\right)$ however showed no significant similarity of rank order.

The use of rates of absence based upon man years means that those who had died or become medically retired during the year might have contributed appreciably to the certified absence of their grade group. Even though the numbers of such staff were small (for example, 25 male senior staff out of about

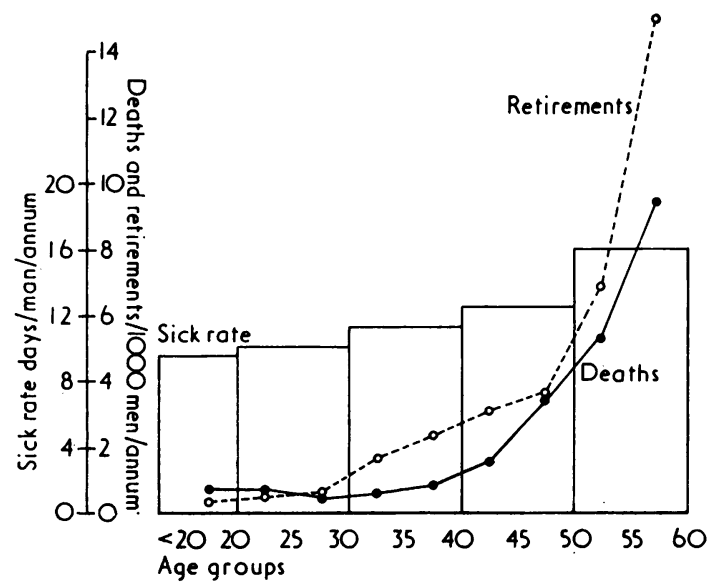

FIG. 1. Sickness absence, deaths, and medical retirements by age in men. Mean annual rates for 1972-75.
4000 and 470 technicians out of 106000 ) and only some of these had taken lengthy absence before they had died or retired, it was thought advisable to remove this source of bias by using absence rates of staff employed throughout each year. This means that recently recruited staff were also excluded and a substantial proportion of these stay only a few weeks. Such short stay employees had previously been shown to take more sickness absence than those who remain in employment. Their exclusion from the full year staff analysis would also reduce the bias that grades with a high labour turnover would show as an unduly high rate of absence.

The rates of medical wastage and of full year staff certified sickness absence duration, standardized for age, for the 11 male grade groups are set out in Table 1 . The values of $r_{s}$ for each of the three years achieved significant levels at $0.764,0.836$, and 0.727 while the correlation between the mean rates for the three years combined was $0 \cdot 827$, significant at the $1 \%$ level. Values for the seven female grades were significant in the first and third year and the means for the three years gave $r_{s}=0.857(P<0.05)$. The threeyear mean rates for men and women are set out in Fig. 2.

For men, the correlation between death rates alone and days of certified absence using untransformed variates was not statistically significant $(r=+0.562)$ although for medical retirements and days of absence the value of +0.785 was significant at the $1 \%$ level, while that for wastage was +0.895 $(\mathrm{P}<0.001)$. Death rates and retirement rates showed little correlation $(\mathrm{r}=+0 \cdot 175)$.

\section{Wastage and absence in geographical regions}

Substantial differences in the crude rates of both wastage and sickness absence have been recorded for Post Office staff between various regions of the United Kingdom for many years. Regions in the north of England, Scotland, Wales, and particularly Northern Ireland usually have had higher rates. In 1974-75 it became possible for the first time to allow for differences both in age structure and occupational structure of staff employed in each region, and thus make more meaningful comparisons. Figures of absence among staff employed throughout the year are not available regionally, so mean staff rates for man or woman years at risk only could be used.

Rates standardized for age and occupational structure for each region (Table 2) show approximately twofold differences between the highest and the lowest. Northern Ireland and the North West region had the highest rates of wastage and of certified absence for both men and women. Wastage correlations using untransformed variates with absence were statistically significant, $r=+0.896$ $(\mathrm{P}<0.001)$ for men, and $\mathrm{r}=+0.851(\mathrm{P}<0.01)$ 
TABLE 1

Medical Wastage per 1000 and Certified Absence Days per Man, Age Standardized, for 11 Male Grade Groups 1972-75

\begin{tabular}{|c|c|c|c|c|c|c|c|c|c|}
\hline \multirow[t]{2}{*}{ Grade group } & \multirow{2}{*}{$\begin{array}{c}\text { Population } \\
\text { October } \\
1974\end{array}$} & \multicolumn{4}{|c|}{ Medical wastage/1000 } & \multicolumn{4}{|c|}{$\begin{array}{c}\text { Full year staff certified absence } \\
\text { days/man }\end{array}$} \\
\hline & & $1972-73$ & $1973-74$ & $1974-75$ & Mean & $1972-73$ & $1973-74$ & $1974-75$ & Mean \\
\hline $\begin{array}{l}\text { Senior staff } \\
\text { Senior engineers } \\
\text { Technicians } \\
\text { Telecommunica- } \\
\text { tions office staff } \\
\text { Postal executives } \\
\text { Postal, clerical } \\
\text { Postmen, higher } \\
\text { Telephonists } \\
\text { Postmen } \\
\text { Telecommunica- } \\
\text { tions, other } \\
\text { Postal, other }\end{array}$ & $\begin{array}{r}3936 \\
13640 \\
106050 \\
15976 \\
12900 \\
15314 \\
17322 \\
14025 \\
86166 \\
\\
7918 \\
10433\end{array}$ & $\begin{array}{l}2 \cdot 18 \\
4 \cdot 23 \\
4 \cdot 90 \\
\\
5 \cdot 57 \\
5 \cdot 16 \\
5 \cdot 46 \\
6 \cdot 71 \\
7 \cdot 12 \\
8 \cdot 46 \\
\\
8 \cdot 12 \\
7 \cdot 94\end{array}$ & $\begin{array}{r}3 \cdot 22 \\
3 \cdot 72 \\
5 \cdot 81 \\
\\
6 \cdot 71 \\
6 \cdot 22 \\
7 \cdot 22 \\
8 \cdot 13 \\
9 \cdot 21 \\
8 \cdot 84 \\
\\
8 \cdot 21 \\
10 \cdot 42\end{array}$ & $\begin{array}{l}3 \cdot 07 \\
3 \cdot 06 \\
5 \cdot 77 \\
\\
5 \cdot 77 \\
7 \cdot 31 \\
6 \cdot 51 \\
7 \cdot 03 \\
8 \cdot 42 \\
8 \cdot 59 \\
9 \cdot 66 \\
9 \cdot 15\end{array}$ & $\begin{array}{l}2 \cdot 62 \\
3 \cdot 67 \\
5 \cdot 49 \\
\\
6 \cdot 02 \\
6 \cdot 23 \\
6 \cdot 40 \\
7 \cdot 29 \\
8 \cdot 25 \\
8 \cdot 63 \\
\\
8 \cdot 66 \\
9 \cdot 17\end{array}$ & $\begin{array}{r}2 \cdot 35 \\
5 \cdot 02 \\
10 \cdot 20 \\
\\
7 \cdot 89 \\
6 \cdot 75 \\
7 \cdot 93 \\
12 \cdot 62 \\
12 \cdot 02 \\
12 \cdot 34 \\
\\
11 \cdot 64 \\
9 \cdot 75\end{array}$ & $\begin{array}{r}4 \cdot 60 \\
5 \cdot 58 \\
9 \cdot 10 \\
\\
7 \cdot 92 \\
7 \cdot 73 \\
9 \cdot 32 \\
12 \cdot 92 \\
9 \cdot 67 \\
13 \cdot 55 \\
\\
13 \cdot 16 \\
11 \cdot 64\end{array}$ & $\begin{array}{r}3 \cdot 38 \\
4 \cdot 38 \\
9 \cdot 41 \\
\\
6 \cdot 87 \\
5 \cdot 76 \\
7 \cdot 53 \\
11 \cdot 07 \\
12 \cdot 92 \\
13 \cdot 25 \\
\\
12 \cdot 53 \\
9 \cdot 34\end{array}$ & $\begin{array}{r}3.44 \\
4 \cdot 99 \\
9 \cdot 57 \\
\\
7 \cdot 56 \\
6 \cdot 75 \\
8 \cdot 26 \\
12 \cdot 20 \\
11 \cdot 54 \\
13 \cdot 05 \\
\\
12 \cdot 44 \\
10 \cdot 24\end{array}$ \\
\hline
\end{tabular}

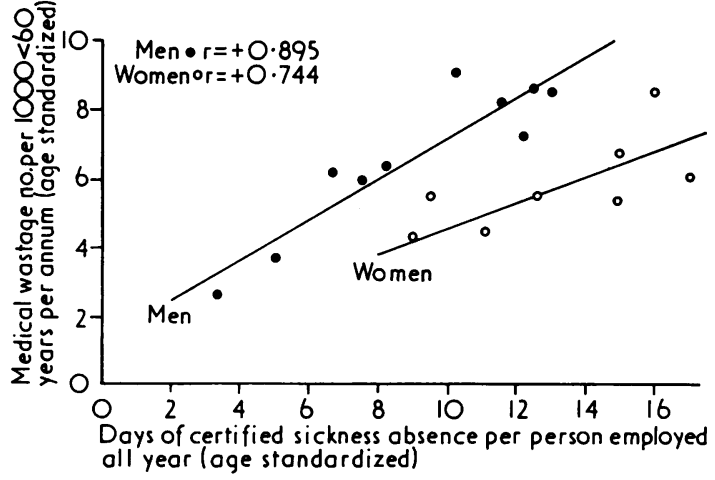

FIG. 2. Mean medical wastage and certified sickness rates by job grades in Post Office for men and women 1972-75. for women, while rank orders were also significantly related ( $r_{s}$ for men $0 \cdot 794$, and for women $0 \cdot 649$ ). The standardized rates are set out for each sex in Fig. 3.

\section{Discussion}

A statistically significant association between medical wastage and the duration of certified sickness absence for men and women, whether grouped by occupation or by geographical region, is consistent with other indirect evidence, although this particular link does not appear to have been previously described.

Socioeconomic status, which depends upon occupation, has long been known to exert a strong influence upon mortality. The standardized mortality ratio (SMR) for men aged 15-64 years in social class I for 1970-72 was 77 and that for class V was 137

\section{Regional Medical Wastage per 1000 and Mean Certified Absence Days of Staff, Job and Age STANDARDIZED, FOR MEN AND WOMEN 1974-75}

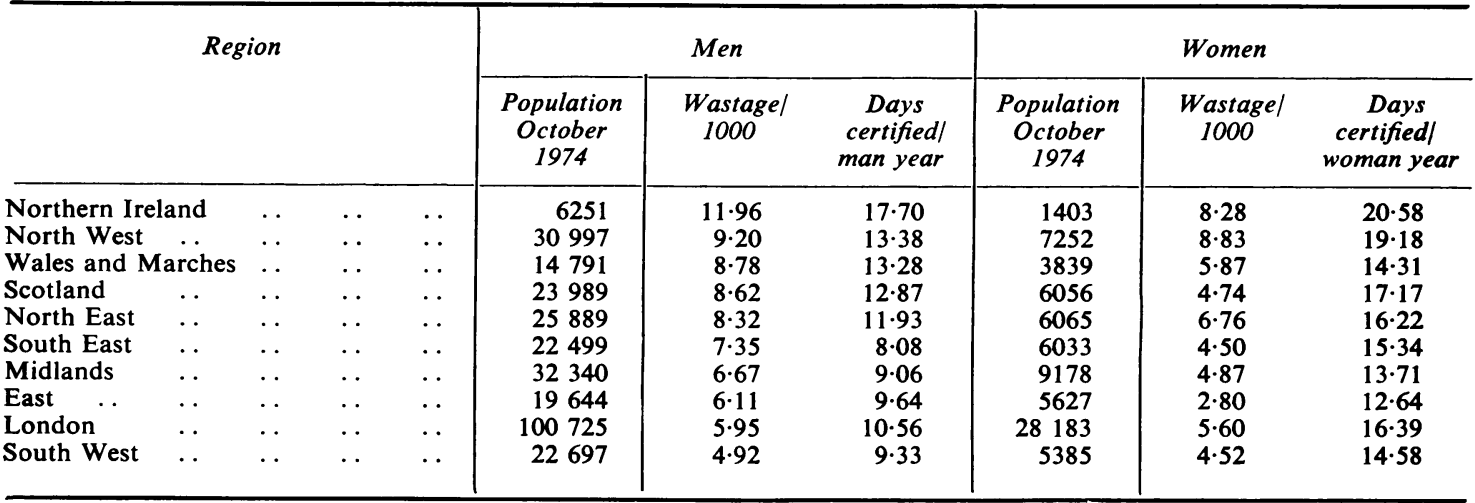




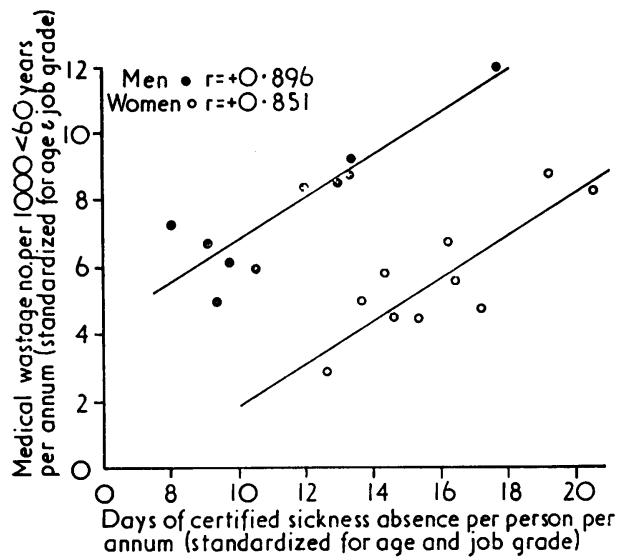

FIG. 3. Medical wastage and certified sickness rates by geographical regions of UK in Post Office for men and women 1974-75.

(Central Statistical Office, 1975). Occupational mortality analyses provide more detailed figures (Registrar General, 1971), but those for 1971 are not yet available. Death rates derived from records of employed people even with full tracing are usually substantially lower than those expected from national rates (Fox and Collier, 1976) and rates for top business executives are particularly low (Metropolitan Life Insurance Company, 1974). Post Office employees are no exception, since death rates of men, including the medically retired and pensioners up to the age of 64 years, are much lower than would be expected from national rates, and SMRs for occupational grades range from 38 to 92 .

Retirement rates due to disablement are not normally reported in the literature, but The General Household Survey (Office of Population Censuses and Surveys, 1975) has shown rates of 'limiting longstanding illness' with patterns similar to those of mortality. Absence from work due to certified incapacity is well known to be highest among semiskilled or unskilled staff, but national rates are not available by occupation apart from one unique and invaluable special study (Ministry of Pensions and National Insurance, 1965) which showed differences between rates in various jobs comparable with those observed in this paper.

Health statistics for various regions of the United Kingdom have long shown marked differences for certified sickness absence, morbidity, and mortality. The most obvious discrepancy between Post Office regional sickness absence rates and those derived from social security statistics relates to Wales. Men in Wales have had more days of certified incapacity than men elsewhere for the past 20 years. In 1972-73 for example, men in Wales had $32 \cdot 2$ days of certified incapacity when the rate for all insured men in the United Kingdom was 16.9 days; men in Northern Ireland took 27.1 (Central Statistical Office, 1975). These 'days' are neither calendar nor working days, but are based on a six-day week (312 day year). Post Office staff, like civil servants and members of the armed services, do not contribute to these social security figures and their rates are measured in calendar days. Comparisons between Post Office and social security rates for regions are best made by using ratios (Table 3 ) in which the standard and Post Office regions have been grouped to resemble each other as far as possible. Only three regions show appreciable differences: Wales, the combination of the standard regions of Yorkshire and Humber with Northern, both of which show social security ratios well above corresponding Post Office regions, and for London and the South East where the Post Office ratio is higher. In all other regions the ratios are similar.

The probable explanation lies in the fact that while Post Office rates are standardized not merely for age, but also for occupation, social security rates are unadjusted. The high ratios for Wales and the North East could be due to a relative preponderance of men in heavy industry including mining, while the low ratio for London and the South East may be due to a relative preponderance of light industry and office work. The small discrepancy for East Anglia may be due to a higher proportion of men employed in agriculture, an occupation known to have low rates of certified incapacity (Ministry of Pensions and National Insurance, 1965). If these assumptions are correct, Post Office standardized rates of certified absence allow more valid regional comparisons than do the unadjusted rates available from social security

\section{TABLE 3}

Certified Sickness Absence Ratios for Men in Standard Regions of UNITED Kingdom. Social SeCurity 1972-73, Post OfFice 1974-75

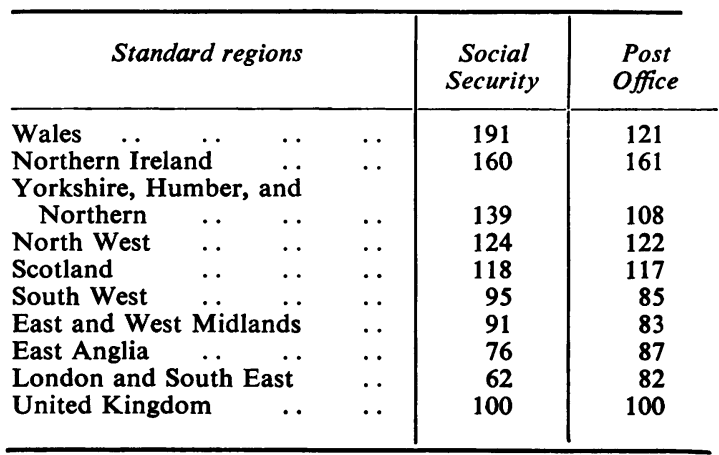


sources. It is difficult to assess the effects of the minor differences in regional boundaries of the two groups but the low population density of the areas involved means that these are not likely to be large, and a gain for one region would be balanced by a loss for the adjacent one.

The demonstration of a close association between medical wastage and certified sickness absence implies that groups with high rates of absence duration are indeed less healthy, since almost all wastage is due to death or long-standing objective disease. Without detracting from the view that motivation, including job satisfaction, is of considerable importance in determining sickness absence, it would seem prudent to recognize that for absence involving spells exceeding a week or so in length, there are also strong links with more objective measures of ill health. Those working in occupations or in geographical regions with the highest rates of medical wastage are the most in need of preventive health care. There is, as yet, little evidence to prove the effectiveness of periodical health screening as it is currently practised in some organizations, but as Holland (1974) observed, selective screening can have a useful place in health care. If this principle can be applied to groups showing high medical wastage it may become easier to demonstrate benefit, either in terms of reduced certified absence or in lowered rates of death or disablement during working life. Since wastage rates, and to a lesser extent sickness absence, are higher in people over the age of 50 years, it would be useful to assess relationships between them for older employees only. This was not possible in the present study since absence data are not available in a form to permit this for occupational or regional groups.

The conclusions drawn in this paper should be verified in other fields of employment, but few organizations of sufficient size maintain records suitable for the purpose. National figures would clearly be the most desirable, but until record linkage can be achieved between social security records of incapacity and death certificates, and accurate descriptions of occupation obtained, there seems little prospect that this can be done.
I am grateful to Dr S. J. Pocock for his suggestions in the preparation of this paper.

\section{References}

Bashford, H. H. (1944). Some aspects of sickness absence. British Medical Journal, 1, 7-10.

Central Statistical Office (1975). Social Trends No.6, pp. 26 and 87. HMSO, London.

Coe, J. (1975). The physician's role in sickness absence certification: a reconsideration. Journal of Occupational Medicine, 17, 722-724.

Committee on Abuse of Social Security Benefits (1973). Cmnd. 5228, pp. 65-69. HMSO, London.

Fox, A. J. and Collier, P. F. (1976). Low mortality rates in industrial cohort studies due to selection for work and survival in the industry. British Journal of Preventive and Social Medicine, 30, 225-230.

Hinkle, L. E. and Wolff, H. G. (1957). The nature of man's adaptation to his total environment and the relation of this to illness. Archives of Internal Medicine, 99, 442-460.

Holland, W. W. (1974). Screening for disease. Taking stock. Lancet, 2, 1494-1497.

Jones, R. M. (1971). Absenteeism. Manpower Paper No. 4. Department of Employment, London.

Long, M. C. W. (1968). In Proceedings of the Symposium on Absence from Work Attributed to Sickness, edited by A. W. Gardner, pp. 23-32. Society of Occupational Medicine, London.

Metropolitan Life Insurance Company (1974). Longevity of corporate executives. Statistical Bulletin, February 1974, pp. 2-4.

Ministry of Pensions and National Insurance (1965). Report on an Enquiry into the Incidence of Incapacity for Work, Part 2. HMSO, London.

Office of Population Censuses and Surveys (1975). The General Household Survey 1972, pp. 197 and 207. HMSO, London.

Registrar General (1971). Decennial Supplement England and Wales 1961. Occupational Mortality Tables. HMSO, London.

Taylor, P. J. (1968). Personal factors associated with sickness absence. British Journal of Industrial Medicine, 25, 106-118.

_ and Pocock, S. J. (1973). Sickness absence. In Occupational Health Practice, edited by R. S. F. Schilling, pp. 211-226. Butterworths, London.

Received for publication 19 March 1976

Accepted for publication 16 June 1976 